\title{
ДИНАМИКА СОСТОЯНИЯ ЗДОРОВЬЯ ДЕТЕЙ, ПОСЕЩАЮЩИХ ДЕТСКИЕ ДОШКОЛЬНЫЕ ОБРАЗОВАТЕЛЬНЫЕ УЧРЕЖДЕНИЯ
}

\section{DYNAMICS OF THE HEALTH STATUS OF CHILDREN ATTENDING PRESCHOOL INSTITUTIONS}

\section{G. Katsova}

N. Maleeva

Summary. The article presents the results of a comparative analysis of the health status of children attending preschool educational institutions in Orenburg for 2011 and 2019. The study of the physical development of the subjects showed an increase in the number of overweight children and a decrease in the number of underweight children in 2019 compared to 2011. Pathology of the cardiovascular, respiratory and digestive systems was the most frequent among the examined children. Differences in the structure of morbidity in children 3-4 and 5-7 years old in the studied periods were established. A comparative analysis of the resistance of the examined children showed an increase in the number of children with low resistance in the 2019 study. A comparative analysis of the distribution of children by health groups in 2011 and 2019 did not reveal significant differences.

Keywords: childrens, preschool educational institutions, a state of health.

\author{
Кацова Галина Борисовна \\ К.м.н., дочент, ГОУ ВПО «Оренбургский \\ государственный медицинский университет» \\ kazovagalina@yandex.ru \\ Малеева Нина Петровна \\ К.м.н., дочент, ГОУ ВПО «Оренбургский \\ государственный медицинский университет»
}

Аннотация. В статье представлены результаты сравнительного анализа состояния здоровья детей, посещающих детские дошкольные образовательные учреждения г. Оренбурга за 2011 и 2019 годы. Изучение физического развития обследуемых показало увеличение числа детей с избыточной массой тела и уменьшение с дефицитом массы тела в 2019 году по сравнению с 2011 годом. Наиболее часто среди обследованных детей встречалась патология сердечно-сосудистой, дыхательной систем и системы пищеварения. Установлены различия в структуре заболеваемости детей 3-4 и 5-7 лет в изучаемые периоды. Сравнительный анализ резистентности обследуемых детей показал увеличение количества детей с низкой резистентностью в исследовании 2019 года. Проведенный сравнительный анализ распределения детей по группам здоровья в 2011 и 2019 годах значимых различий не выявил.

Ключевые слова: состояние здоровья, дети, детские дошкольные образовательные учреждения.

\section{Цель исслеАования}

Изучить динамику состояния здоровья детей, посещающих детские дошкольные образовательные учреждения, в катамнезе (2011-2019 годы).

\section{Материалы и методы исследования}

Состояние здоровья и физическое развитие детей изучалось по данным $\phi .112 /$ «История развития ребенка» и ф. 026/у «Медицинская карта ребенка для образовательных учреждений дошкольного образования».

В обследование были включены 96 детей от 3 до 7 лет, посещающих детские дошкольные образовательные учреждения (ДОУ), проживающих в г. Оренбурге и не имеющих на момент осмотра признаков острых заболеваний. В процессе исследования у детей оценивались уровень и гармоничность физического развития, уровень нервно-психического развития, изучалась заболеваемость детей различных возрастных групп, степень резистентности организма и распределение обследуемых по группам здоровья. 


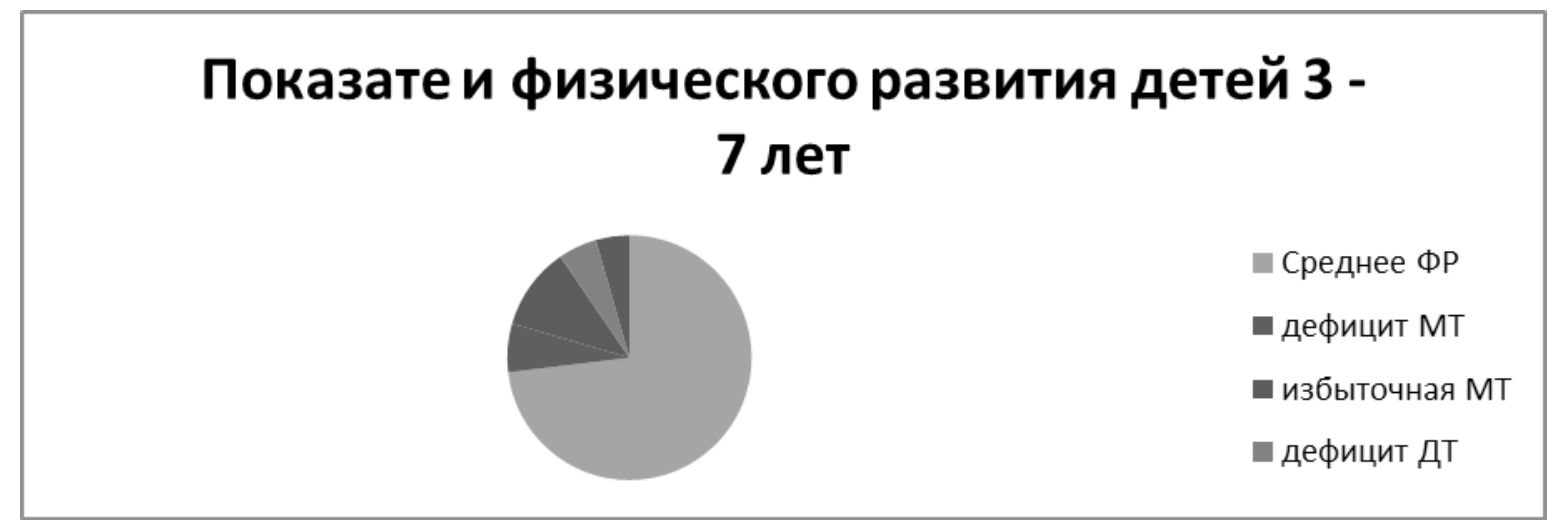

Рис. 1. Средние показатели физического развития детей 3-7 лет (2019 год)
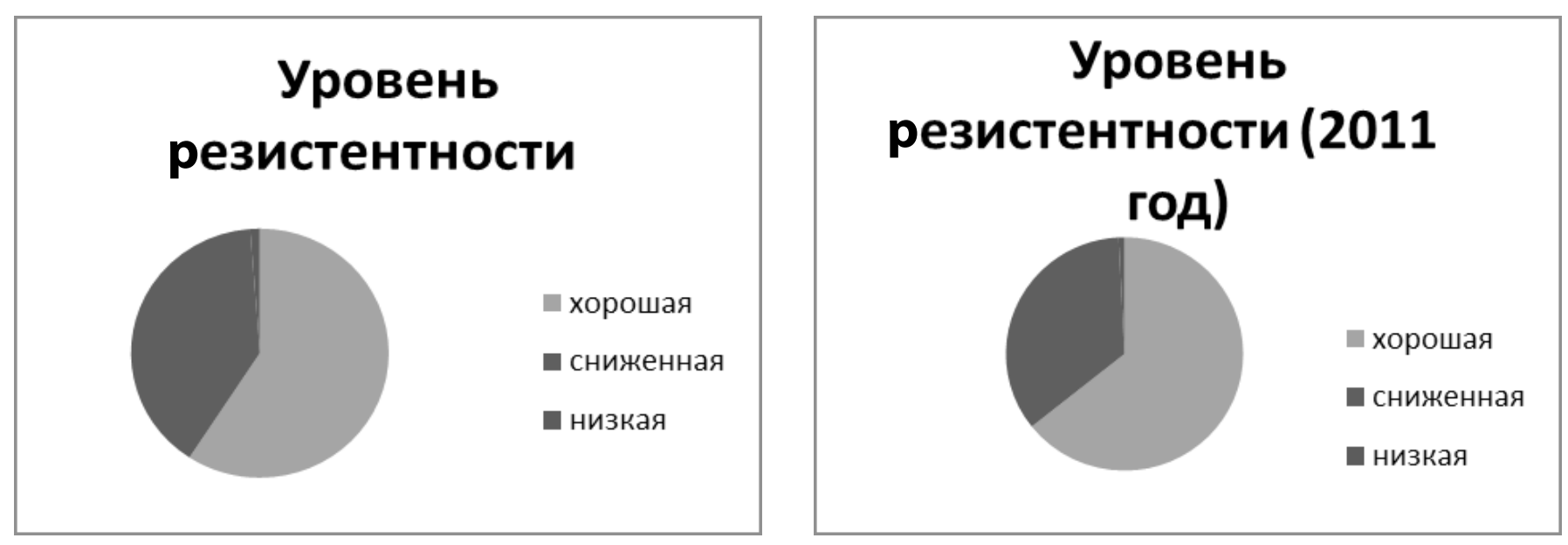

Рис. 2. Сравнительный уровень резистентности у детей (2019 и 2011 годы)

Полученные в исследовании 2019 года данные сравнивались с показателями исследований, проводимых в 2011 году.

\section{Результаты \\ исслеАования}

По результатам проведенного исследования, 72,4\% детей имели средние показатели физического развития. Дети с дефицитом массы тела составляли 6,3\% обследованных (9,3\% в 2011 году), у 10,5\% этой группы длина тела соответствовала нормальным показателям (6,5\% в 2011 году).

Дети с избыточной массой тела составляли 10,8\% при 4,3\% обследованных в 2011 году.

В результате обследования выявлено, что 4,8\% детей имели низкую длину тела, а 4,2\% длину тела, превышающую нормальные показатели (рис. 1).
Изучение нервно-психического развития показало, что первой группе оно соответствовало у 91,7\% детей в возрасте 3 лет. Отставание нервно-психического развития на 1-2 эпикризных срока имели 5,2\% обследованных.

В возрасте 4-7 лет отставание эмоционального и психомоторного развития имели $12,3 \%$ детей $(10,9 \%$ в 2011 году).

Степень резистентности оценивалась по количеству эпизодов острых инфекционных заболеваний в течение одного года. Хорошая резистентность организма (до 3 эпизодов в год) выявлена у 59,2\%, сниженная резистентность организма (4-5 эпизодов в год) у 39,6\% и низкая резистентность (6 и более эпизодов в год) у 1,2\% обследованных (64,3\%; 34,9\%; 0,8\% соответственно в 2011 году) (рис. 2).

При изучении заболеваемости детей, посещающих ДОУ, наиболее часто встречались болезни органов кро- 


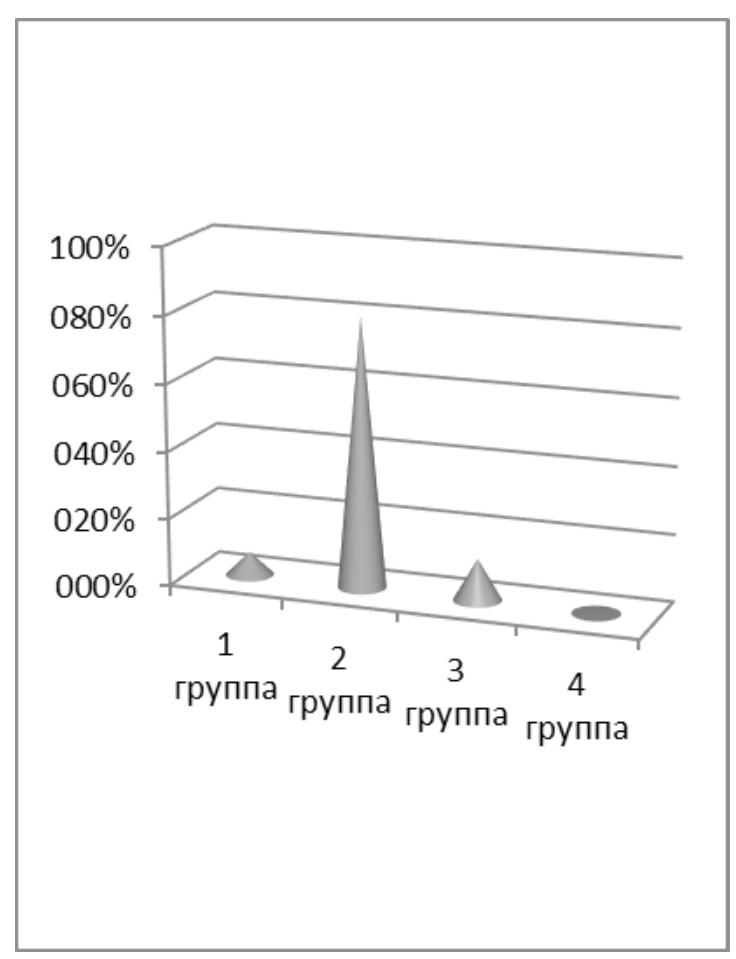

Рис. 3. Распределение детей по группам здоровья (2011 год)

вообращения, пищеварения и системы дыхания. Отмечена зависимость заболеваний от возраста ребенка. Для детей 3-4 лет более характерными были болезни органов дыхания (22,8\% - 23,5\% при 13\% - 15\% в 2011 году). Болезни органов пищеварения в этом возрасте встречались у $15,2 \%-18,6 \% \%$ детей (при $26,7 \%-28,2 \%$ в 2011 году).

В возрасте 5-7 лет заболевания органов пищеварения диагностированы у 42,6\% - 44,7\% детей при $46,8 \%$ - 49,9\% детей в 2011 году, а органов дыхания у $15 \%$ - 18\% детей при 18,6\% - 22,9\% в 2011 году.

Среди заболеваний пищеварительной системы наиболее часто встречались кариез и дисфункция желчевыделительной системы.

Морфофункциональные изменения системы дыхания чаще проявляются в виде гипертрофии миндалин и аденоидов II степени, аллергического риносинусита, реже рецидивирующие острые респираторные заболевания.

Заболевания системы кровообращения у детей дошкольного возраста встречались с одинаковой частотой - 22,8-36\%. Со стороны сердечно-сосудистой системы превалировали ЭКГ-синдромы и малые аномалии сердца.

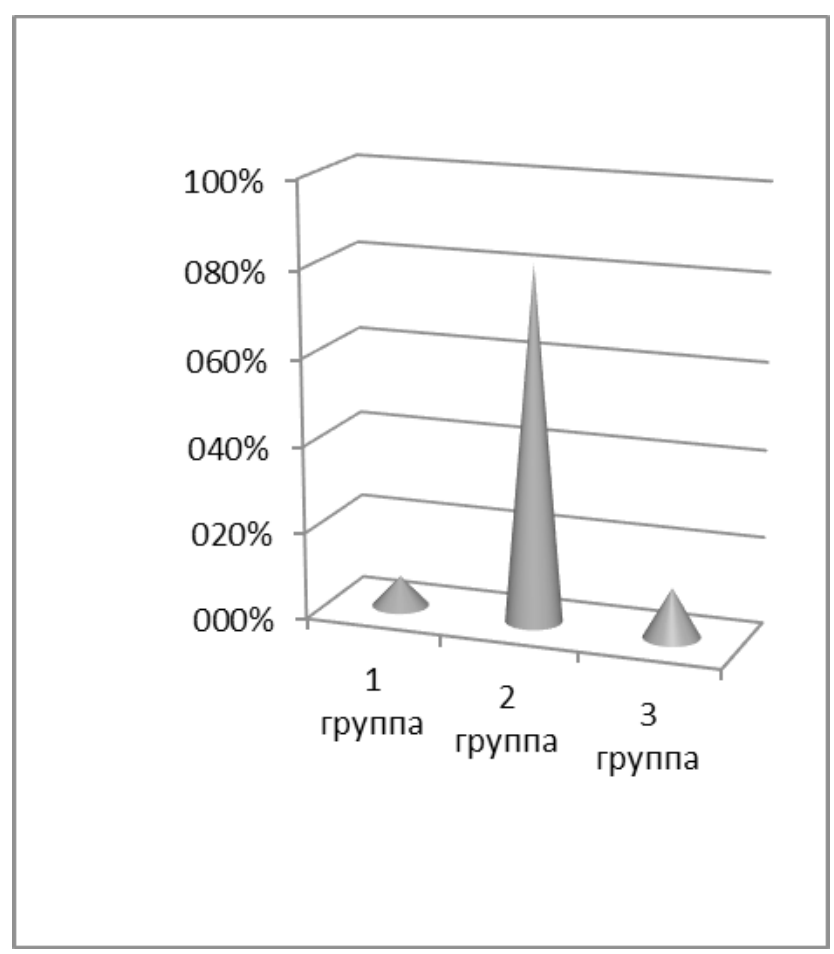

Рис. 4. Распределение детей по группам здоровья (2019 год)

У детей младшего и дошкольного возраста заболевания эндокринной, нервной, костно-мышечной систем, болезни глаз и его придаточного аппарата, врожденные аномалии, психические заболевания и расстройства поведения встречались значительно реже $(10,8 \%, 7,8 \%$, $5,7 \%, 4,4 \%, 1,9 \%$ соответственно). Значимых различий с их встречаемостью в 2011 году не выявлено.

По результатам комплексной оценки состояния здоровья детей, посещающих дОУ, к первой группе здоровья были отнесено 6,9\%, ко второй группе - 81,7\%, к третьей - 11,4\% обследуемых. Детей с четвертой и пятой группами здоровья, посещающих детские образовательные учреждения, не выявлено (рис. 3,4$)$

Среди детей третьей группы здоровья чаще встречались дети с плоскостопием - 22,5\%, сколиозом II степени - 5,2\%, гиперметропией средней и высокой степени - 20,1\%, атопическим дерматитом - 16,3\%, хроническим гастритом - 3,3\%, хроническим тонзиллитом - 12,8\% (при 21,9\%; 4,7\%; 17,1\%; 14,1\%; 4,7\%; 10,9\% соответственно в 2011 году). Как правило, у детей, отнесенных к третьей группе здоровья, выявлено только одно хроническое заболевание, что совпадало с данными исследований 2011 года (86,9\% при 87,3\% в 2011 году).

Первая группа здоровья чаще встречалась у детей в возрасте 3 лет (19,7\% при 17,0\% в 2011 году). Затем с воз- 
растом их количество уменьшалось и с 5 лет оставалось относительно стабильным, составляя не более 7,2-8,0\%. Это может быть связано с тем, что до 3 лет основное группа детей не посещает детские образовательные учреждения и имеет небольшое количество контактов с больными сверстниками. Таким образом, к поступлению в школу у 92\% детей выявлялись отклонения здоровья или факторы риска его нарушения различной степени.

\section{Обсужление результатов и выво ы}

Анализ результатов проведенного исследования показал, что:

1. за последние 8 лет на $6,5 \%$ увеличилось количество детей с избыточной массой тела в возрасте 3-7 лет, посещающих детские дошкольные образовательные учреждения;

2. количество детей с дефицитом массы тела сократилось на 3,0\%;

3. снизилось количество детей с хорошей резистентностью организма, при этом достоверно увеличился контингент детей, имеющих низкую резистентность организма;

4. Изменилась структура заболеваемости у детей в различных возрастных группах за счет превалирования болезней органов дыхания у детей
3-4 лет и болезней системы пищеварения в возрасте 5-7 лет;

5. достоверных различий заболеваний сердечно - сосудистой, эндокринной, костно-мышечной, нервной систем организма, а также болезней глаз и его придаточного аппарата, врожденных аномалий не выявлено;

6. распределение детей по группам здоровья достоверных различий по сравнению с 2011 годом не имело.

Таким образом, полученные результаты показали, что наиболее значимые изменения состояния здоровья детей 3-7 лет, посещающих детские дошкольные учреждения, выявлены в отношении повышения массы тела и снижения резистентности организма. Последнее требует более детального изучения, так как с этим возможно связано увеличение количества детей с патологией дыхательной системы. Увеличение количества детей с избыточной массой тела в младшем и дошкольном возрасте в дальнейшем может привести к развитию эндокринной патологии, что обуславливает необходимость усиления контроля за питанием детей и расширения методов просветительской работы с родителями по вопросам правильного питания и стимуляции двигательной активности ребенка.

\section{ЛИТЕРАТУРА}

1. Егорова М.С., Ханбикова Э. Р., Пичугина Н. Н. Динамическая оценка групп здоровья детей, посещающих дошкольные образовательные учреждения. // Международный студенческий научный вестник. -2018.-№ 6. С. 21-23

2. Перепелкина Н.Ю., Павловская О. Г., Кузьмин С. А. Динамика основных показателей здоровья детей и подростков в Оренбургской области. //0бщественное здоровье и здравоохранение.-2008.-№ 4. С. 8-12

3. Колесников Л.И., Долгих В. В., Рычков Л. В. и др. Особенности формирования здоровья детей, проживающих в промышленных центрах. //Бюллетень Сибирского отделения РАМН.-2008.-№ 4. С. 72-76

4. Мурзина Ю.М., Кацова Г.Б. Состояние здоровья детей, посещающих детские дошкольные образовательные учреждения г. Оренбурга (по результатам профилактических медицинских осмотров). //Вестник Российского университета дружбы народов. Серия: Медицина. — 2009.-№ 4. С. 28-31

5. Баширова Г.И., Малиевский В.А. Состояние здоровья детей 5-7 -летнего возраста, посещающих дошкольные образовательные учреждения. //Российский педиатрический журнал. — 2014.— № 3. С. 18-20

(c) Кацова Галина Борисовна ( kazovagalina@yandex.ru ), Малеева Нина Петровна.

Журнал «Современная наука: актуальные проблемы теории и практики» 